\title{
Implementasi Data Mining Untuk Analisa Tingkat Pelanggaran Lalu Lintas Dengan Algoritma Association Rule
}

\author{
Yera Wahda Wahdi \\ UNIVERSITAS PUTERA BATAM \\ e-mail : Yerawahdawahdi@vahoo.com
}

\begin{abstract}
Kepolisian berkaitan dengan fungsinya sebagai pengayom masyarakat diharapkan mampu mengambil tindakan dalam menyikapi pelanggaran lalu lintas dengan melakukan operasi razia dalam mengungkap pelanggaran yang dapat dilakukan dengan menggunakan teknik analisis dari kebiasaan seberapa sering pelanggaran lalu lintas dilakukan. Pendeteksian pelanggaran lalu lintas yang sering terjadi secara bersamaan disebut Association Rule.
\end{abstract}

Kata Kunci : Data Mining, FP-Growth

\section{PENDAHULUAN}

\subsection{Latar Belakang Masalah}

Pelanggaran lalu lintas sudah membudaya di masyarakat, tidak tekecuali terjadi diwilayah Kota Padang. Dengan statusnya sebagai ibukota provinsi dan kota besar yang memiliki tingkat kepadatan penduduk paling tinggi di Provinsi Sumatera Barat, tentunya menjadikan Kota Padang sebagai Kota yang mempunyai tingkat kepadatan kendaraan bermotor paling tinggi jika dibandingkan dengan wilayah lainnya. Kota Padang merupakan salah satu kota besar yang memiliki data jumlah kecelakaan terbesar terbukti dari data tahun 2012 hingga 2013, Kota Padang berada diposisi peringkat pertama kasus kecelakaan terbanyak di Provinsi Sumatera Barat. Pada tahun 2012, di Kota Padang tercatat 540 kasus kecelakaan, dengan rincian 80 korban meninggal dunia [1].

Kepolisian berkaitan dengan fungsinya sebagai pengayom masyarakat diharapkan mampu mengambil tindakan dalam menyikapi pelanggaran lalu lintas dengan melakukan operasi razia dalam mengungkap pelanggaran yang dapat dilakukan dengan menggunakan teknik analisis dari kebiasaan seberapa sering pelanggaran lalu lintas dilakukan. Pendeteksian pelanggaran lalu lintas yang sering terjadi secara bersamaan disebut Association Rule.

Analisis asosiasi dikenal juga sebagai salah satu teknik data mining yang menjadi dasar dari berbagai teknik data mining lainnya. Khususnya salah satu tahap dari analisis asosiasi yang disebut analisis pola frequensi tinggi (frequent pattern mining) menarik perhatian banyak peneliti untuk menghasilkan algoritma yang efisien. Penting tidaknya suatu aturan assosiatif dapat diketahui dengan dua parameter, support (nilai penunjang) yaitu persentase kombinasi item tersebut dalam database dan confidence [2].

Dalam penelitian ini, algoritma yang digunakan adalah Frequent Pattern-Growth (FP-Growth) yaitu pengembangan dari metode Apriori yang merupakan salah satu alternatif untuk menentukan himpunan data yang paling sering muncul (frequent itemset) dalam sebuah kumpulan data dengan membangkitkan struktur data Tree atau disebut dengan Frequent Pattern Tree (FPTree) [3].

\subsection{Perumusan Masalah}

Berdasarkan latar belakang yang diuraikan, maka terdapat beberapa hal yang menjadi permasalahan penelitian, yaitu :

1. Bagaimana menerapkan teknik Association Rule pada data pelanggaran lalu lintas hingga diketahui pola hubungannya dengan pengguna jalan?

2. Bagaimana menganalisa tingkat pelanggaran lalu lintas dengan menggunakan Data Mining Association Rule untuk melihat jenis kesalahan?

3. Bagaimana menguji pola yang telah ditemukan dengan 
memanfaatkan software aplikasi yang menerapkan teknik Data Mining aturan asosiasi dengan algoritma Apriori?

\subsection{Batasan Masalah}

Agar lebih jelas dan terarah serta tidak terjadinya banyak masalah yang akan timbul, maka penulis hanya akan memberikan batasan-batasan sebagai berikut :
1. Tools yang digunakan adalah RapidMiner

2. Penelitian dilakukan pada POLRESTA Padang

Menggunakan Data Mining Association Rule untuk menghasilkan rules dan Algoritma FP-Growth untuk menemukan pola kombinasi itemset.

\subsection{Tujuan Penelitian}

Dalam melakukan penelitian ini ada beberapa tujuan yang ingin dicapai oleh penulis yaitu :

1. Untuk mengetahui bentuk-bentuk pelanggaran lalu lintas yang terjadi di wilayah POLRESTA Padang dan mengetahui kewenangan aparat kepolisian dalam penyidikan tindak pidana pelanggaran lalu lintas

2. Menganalisa pelanggaran lalu lintas di polresta padang dengan menggunakan Association Rule

3. Merancang metode Association Rule untuk penanganan pelanggaran lalu lintas sehingga dapat meningkatkan efektifitas dan efesiensi kinerja kepolisian.

4. Membangun suatu pengetahuan baru dalam menganalisa tingkat pelanggaran lalu lintas sehingga dapat meningkatkan kesadaran dan ketertiban pengguna jalan.

5. Menguji data pelanggaran lalu lintas dengan menggunakan Tools RapidMiner. sehingga informasi ini dapat membantu kepolisian dalam mengatasi tingkat pelanggaran lalu lintas.

\section{LANDASAN TEORI}

Landasan teori merupakan panduan untuk membahas tentang teori pemecahan masalah yang dihadapi. Dalam hal ini akan dikemukakan beberapa teori yang berhubungan dengan masalah yang dibahas dalam penelitian ini.
Teori-teori yang menjadi landasan dalam penulisan tesis ini antara lain teori Data Mining, Algoritma FP-Growth dengan aturan asosiasi.

\subsection{Data Mining}

Data mining merupakan penemuan informasi baru dengan mencari pola atau aturan tertentu dari sejumlah data yang sangat besar [4]. Data mining atau sering disebut sebagai knowledge discovery in database (KDD) adalah kegiatan yang meliputi pengumpulan, pemakaian data historis untuk menemukan keteraturan, pola atau hubungan dalam data berukuran besar. Keluaran data mining ini bisa dipakai untuk membantu pengambilan keputusan di masa depan. Pengembangan KDD ini menyebabkan penggunaan pattern recognition semakin berkurang karena telah menjadi bagian data mining [5].

\subsection{Pengelompokan Data Mining}

Goldie Gunadi dan Dana Indra Sensuse (2012) menyatakan bahwa menurut Larose dalam bukunya yang berjudul "Discovering Knowledge in Data: An Introduction to Data Mining", Data Mining dibagi menjadi beberapa kelompok berdasarkan tugas/pekerjaan yang dapat dilakukan, yaitu :

1. Deskripsi

Terkadang peneliti dan analisis secara sederhana ingin mencoba mencari cara untuk menggambarkan pola dan kecenderungan yang terdapat dalam data. Deskripsi dari pola kecenderungan sering memberikan kemungkinan penjelasan untuk suatu pola atau kecenderungan.

2. Estimasi

Estimasi hampir sama dengan klasifikasi, kecuali variabel target estimasi lebih ke arah numerik dari pada ke arah kategori. Model dibangun menggunakan baris data (record) lengkap yang menyediakan nilai dari variabel target sebagai nilai prediksi.

Selanjutnya, pada peninjauan berikutnya estimasi nilai dari variabel target dibuat berdasarkan nilai variabel prediksi.

3. Prediksi

Prediksi hampir sama dengan klasifikasi dan estimasi, kecuali bahwa dalam prediksi nilai dari hasil akan ada 
di masa mendatang. Beberapa metode dan teknik yang digunakan dalam klasifikasi dan estimasi dapat pula digunakan (untuk keadaan yang tepat) untuk prediksi.

4. Klasifikasi

Dalam klasifikasi, terdapat target variabel kategori. Sebagai contoh, penggolongan pendapatan dapat dipisahkan dalam tiga kategori, yaitu pendapatan tinggi, pendapatan sedang, dan pendapatan rendah.

5. Pengklasteran (Clusterring)

Pengklasteran merupakan pengelompokan record, pengamatan, atau memperhatikan dan membentuk kelas obyek-obyek yang memiliki kemiripan. Klaster adalah kumpulan record yang memiliki kemiripan satu dengan yang lainnya dan memiliki ketidakmiripan record dalam klaster yang lain. Berbeda dengan klasifikasi, pada pengklasteran tidak ada variabel target. Pengklasteran tidak melakukan klasifikasi, mengestimasi, atau memprediksi nilai dari variabel target, akan tetapi, algoritma pengklasteran mencoba untuk melakukan pembagian terhadap keseluruhan data menjadi kelompok-kelompok yang memiliki kemiripan (homogen), yang mana kemiripan record dalam satu kelompok akan bernilai maksimal, sedangkan kemiripan dengan record dalam kelompok lain akan bernilai minimal.

6. Asosiasi

Tugas asosiasi dalam Data Mining adalah untuk menemukan atribut yang muncul dalam satu waktu. Salah satu implementasi dari asosiasi adalah market basket analysis atau analisis keranjang belanja, sebagaimana yang akan dibahas dalam penelitian ini.

\subsection{Association Rule}

Analisis asosiasi atau association rule mining adalah teknik data mining untuk menemukan aturan assosiatif antara suatu kombinasi item. Algoritma aturan asosiasi akan menggunakan data latihan, sesuai dengan pengertian data mining, untuk menghasilkan pengetahuan. Pengetahuan apakah yang hendak dihasilkan dalam aturan asosiasi? Pengetahuan untuk mengetahuan item-item belanja yang sering dibeli secara bersamaan dalam suatu waktu. Aturan asosiasi yang berbentuk "if...then..." atau "jika...maka..." merupakan pengetahuan yang dihasilkan dari fungsi aturan asosiasi [6].

\subsection{Tahapan Association Rules}

Analisis asosiasi dikenal juga sebagai salah satu teknik data mining yang menjadi dasar dari berbagai teknik data mining lainnya. Khususnya salah satu tahap dari analisis asosiasi yang disebut analisis pola frequensi tinggi (frequent pattern mining) menarik perhatian banyak peneliti untuk menghasilkan algoritma yang efisien. Penting tidaknya suatu aturan assosiatif dapat diketahui dengan dua parameter, support (nilai penunjang) yaitu persentase kombinasi item tersebut dalam database dan confidence [7] .

\section{A. Data Preparation.}

Pada banyak bidang keilmuan, terutama komputer sains, diperlukan data yang berkualitas melalui proses preparation dari data mentah. Dalam prakteknya, ditemukan bahwa data cleaning dan preparation membutuhkan total usaha $80 \%$ dari usaha untuk merekayasa data, sehingga menjadikan data preparation sebagai proses yang krusial. Pentingnya proses ini dapat dilihat dari tiga aspek, yakni:

1. Data real world merupakan data kotor. Data real world bisa mengandung data yang tidak, terdapat noise, tidak konsisten, yang dikarenakan:

a. Tidak lengkap (incomplete), yaitu kekurangan nilai atribut atau hanya mengandung agregat data (contoh : address $="$ ")

b. Noise, yaitu masih mengandung error dan outliers.

c. Tidak konsisten (inconsistent), yaitu data yang mengandung discrepansi dalam code dan nama atau singkatnya datanya tidak konsisten. 2. Sistem mining dengan performa tinggi membutuhkan data yang berkualitas. Data preparation atau preparation menghasilkan dataset yang lebih sedikit daripada dataset 
yang asli, ini bias meningkatkan efisiensi dari data mining. Langkah ini mengandung:

a. Memilih data yang relevan

b. Mengurangi data

3. Data yang berkualitas menghasilkan pola yang berkualitas. Dengan data preparation, maka data yang dihasilkan adalah data yang berkualitas, yang mengarah pada pola yang berkualitas pula dengan:

a. Mengembalikan data yang tidak lengkap

b. Membenarkan eror, atau menghilangkan outliers

c. Membenahi data yang

bertentangan.

\subsection{Algoritma FP-Growth}

Frequent Pattern Growth (FP-Growth) adalah salah satu alternatif algoritma yang dapat digunakan untuk menentukan himpunan data yang paling sering muncul (frequent itemset) dalam sebuah kumpulan data (david, 2008). Algoritma FP-Growth merupakan pengembangan dari algoritma Apriori. Sehingga kekurangan dari algoritma Apriori diperbaiki oleh algoritma FP-Growth [8] .

FP-Growth menggunakan konsep pembangunan tree dalam pencarian frequent itemsets. Hal tersebutlah yang menyebabkan algoritma FP-Growth lebih cepat dari algoritma Apriori. Karakteristik algoritma FP- Growth adalah struktur data yang digunakan adalah tree yang disebut dengan FP-Tree. Dengan menggunakan FP-Tree, algoritma FP- Growth dapat langsung mengekstrak frequent itemset dari FP-Tree.

FP-tree merupakan

struktur penyimpanan data yang dimampatkan. FPtree dibangun dengan memetakan setiap data transaksi ke dalam setiap lintasan tertentu dalam FP-tree. Karena dalam setiap transaksi yang dipetakan, mungkin ada transaksi yang memiliki item yang sama, maka lintasannya memungkinkan untuk saling menimpa. Semakin banyak data transaksi yang memiliki item yang sama, maka proses pemampatan dengan struktur data FP- tree semakin efektif. Kelebihan dari FP-tree adalah hanya memerlukan dua kali pemindaian data transaksi yang terbukti sangat efisien. Misal $\mathrm{I}=\{\mathrm{a} 1, \mathrm{a} 2, \ldots, \mathrm{an}\}$ adalah kumpulan dari item. Dan basis data transaksi $\mathrm{DB}=\{\mathrm{T} 1, \mathrm{~T} 2, \ldots, \mathrm{Tn}\}$, di mana $\mathrm{Ti}$ (i $€[1 . . n])$ adalah sekumpulan transaksi yang mengandung item di I. Sedangkan support adalah penghitung (counter) frekuensi kemunculan transaksi yang mengandung suatu pola. Suatu pola dikatakan sering muncul (frequent pattern) apabila support dari pola tersebut tidak kurang dari suatu konstanta $£$ (batas ambang minimum support) yang telah didefinisikan sebelumnya. Permasalahan mencari pola frequent dengan batas ambang minimum support count $£$ inilah yang dicoba untuk dipecahkan oleh FP- Growth dengan bantuan Struktur FP-tree.

Penggalian itemset yang frequent dengan menggunakan algoritma FP-Growth akan dilakukan dengan cara membangkitkan struktur data tree (FP-Tree). Metode FPGrowth dapat dibagi menjadi 3 tahapan utama yaitu sebagai berikut [9] :

1. Tahap Pembangkitan conditional pattern base

Conditional Pattern Base merupakan subdatabase yang berisi prefix path (lintasan prefix) dan suffix pattern (pola akhiran). Pembangkitan conditional pattern base didapatkan melalui FP-tree yang telah dibangun sebelumnya.

2. Tahap pebangkitan conditional FP-Tree Pada tahap ini, support count dari setiap item pada setiap conditional pattern base dijumlahkan, lalu setiap item yang memiliki jumlah support count lebih besar sama dengan minimum support count $£$ akan dibangkitkan dengan conditional FPtree.

3. Tahap pencarian frequent itemset Apabila Conditional FP-tree merupakan lintasan tunggal (single path), maka didapatkan frequent itemset dengan melakukan kombinasi item untuk setiap conditional FP-tree. Jika bukan lintasan tunggal, maka dilakukan pembangkitan FP-growth secara rekursif.

Ketiga tahap tersebut merupakan langkah yang akan dilakukan untuk mendapat frequent

itemset, yang dapat dilihat pada algoritma berikut :

Input : FP-Tree Tree 
Output : Rt sekumpulan lengkap pola frequent

Method : FP-growth (Tree, null)

Procedure : FP-growth (Tree, _)

\{

01: if Tree mengandung single path $P$;

02: then untuk tiap kombinasi (dinotasikan

_) dari node-node dalam path do

03: bangkitkan pola _ _ dengan support dari

node-node dalam _;

04: else untuk tiap a1 dalam header dari Tree

do

\{

05: bangkitkan pola

06: bangun $_{-}=\mathrm{a} 1{ }_{-}$dengan support $=\mathrm{a} 1$.

support

07: if Tree ${ }_{-}$

08: then panggil FP-growth (Tree, _) \} \}

\section{ANALISA DAN PEMBAHASAN}

3.1 Analisa Data mining dengan Algoritma FP-Growth

Dalam penelitian ini menerapkan Data Mining aturan asosiasi dengan algoritma FPGrowth dalam menganalisa data pelanggaran lalu lintas di Polresta Padang untuk mendapatkan pola pelanggaran yang terjadi. Pola yang ada menggambarkan sebab dan akibat terjadinya pelanggaran lalu lintas di Polresta.

Pada proses pencarian aturan asosiasi pelanggaran lalu lintas semua itemset yang ada dianggap sebagai input pada Data Mining. Seluruh itemset diolah menggunakan algoritma FP-Growth sehingga terbentuk hubungan asosiasi antar itemset dengan memenuhi minimum support dan minimum confidence untuk menetapkan data yang valid. Data yang dihasilkan dianalisa dengan aturan asosiasi "if" - "then". Untuk mencapai semua tahapan tersebut maka langkah pertama yang dilakukan adalah mengumpulkan data. Untuk melakukan penggalian data pelanggaran lalu lintas, penulis menggunakan algoritma FP-Growth. Untuk Frekuensi kemunculan tiap item dari data transaksi dapat dilihat pada tabel berikut :

\begin{tabular}{|c|l|l|}
\hline Tid & Itemset & Frekuensi \\
\hline 1 & Pelajar & 6 \\
\hline 2 & Karyawan & 5 \\
\hline 3 & Supir & 3 \\
\hline 4 & Mobil & 4 \\
\hline 5 & Motor & 7 \\
\hline 6 & Bus Truck & 3 \\
\hline 7 & SIM & ii \\
\hline S & STNK & 6 \\
\hline 9 & Perlengkapan & 10 \\
\hline 10 & Rambu-rambu & 6 \\
\hline
\end{tabular}

3.2 Pembentukan FP-Tree

\begin{tabular}{|c|l|}
\hline TID & Dataset Pelanggaran \\
\hline 1 & $\left(\mathrm{a} \cdot \mathrm{e}^{\wedge} \mathrm{Td}\right)$ \\
\hline 2 & $\mathrm{CMi})$ \\
\hline 3 & \\
\hline 4 & \\
\hline 5 & $\left(\mathrm{a} \cdot \mathrm{e}^{\wedge} \mathrm{TU}\right)$ \\
\hline 6 & $\left(\mathrm{a}, \mathrm{d}^{\wedge} 4 \mathrm{i} 4 \mathrm{j}\right)$ \\
\hline 7 & $\mathrm{t}=\mathrm{esl}$ \\
\hline $\mathrm{S}$ & \\
\hline 9 & $(=£ g £)$ \\
\hline 10 & $(\mathrm{M} 4)$ \\
\hline 11 & $\left(\mathrm{a}, \mathrm{e}^{\wedge} \mathrm{Ji} 4\right)$ \\
\hline 12 & \\
\hline 13 & \\
\hline 14 & \\
\hline
\end{tabular}

Dari Tabel diatas, langkah selanjutnya yang harus dilakukan adalah membentuk jalur FPTree. Dimana hasil pembentukan jalur 1 sampai 14 dapat dilihat di gambar berikut : 


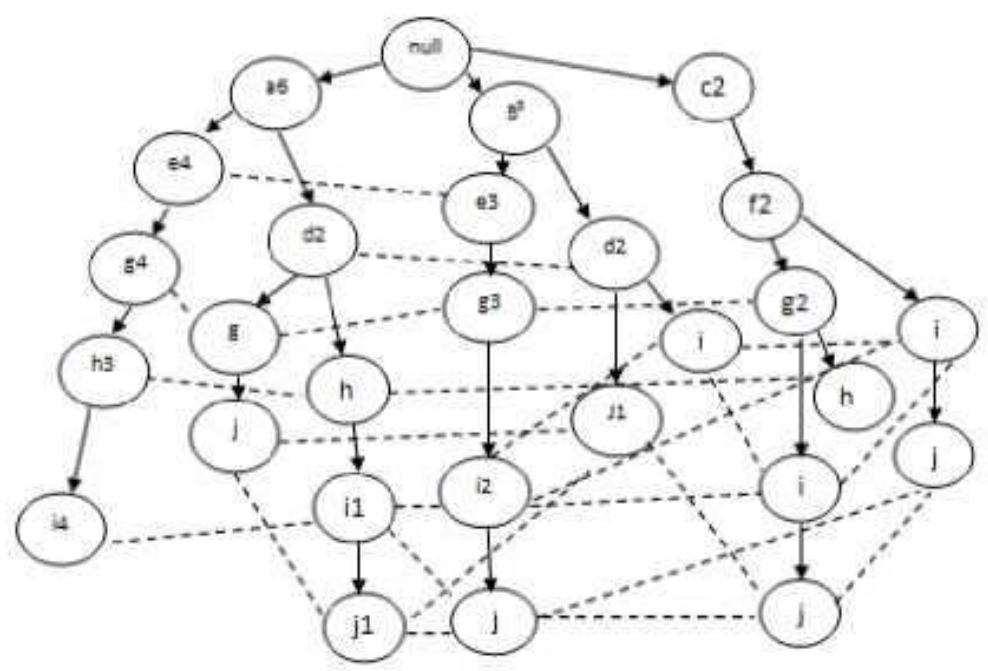

\subsection{Penerapan FP-Growth}

Setelah tahap pembangunan $F P$-tree data pelanggar yang ada, selanjutnya diterapkan algoritma FP-growth untuk mencari frequent itemset. Algoritma FPgrowth dibagi menjadi tiga langkah yaitu Conditional Pattern Base, Conditional FPTree, dan Frequent Itemset.

Conditional Pattern Base merupakan subdatabase yang berisi prefix path (lintasan prefix) dan suffix pattern (pola akhiran). Pembangkitan conditional pattern base didapatkan melalui FP-tree yang telah dibangun. Dari hasil pembentukan FP-Tree sebelumnya maka langkah yang dilakukan adalah membangkitkan conditional FP-Tree untuk lintasan yang mengandung suffix $\mathrm{j}$ sampai suffix a

Hasil dari pembangkitan FP-Tree maka didapatkan Conditional Pattern Base. Hasilnya dapat dilihat pada tabel berikut :

\begin{tabular}{|c|c|}
\hline Suffix & Conditional Pattern Base \\
\hline $\mathrm{j}$ & $\{(\mathrm{i}, \mathrm{d}, \mathrm{g}: \mathrm{l}),(\mathrm{i}, \mathrm{dJixl}),(\mathrm{b}, \mathrm{e}, \mathrm{ga}: \mathrm{l}),(\mathrm{b}, \mathrm{d}: \mathrm{l}), \mathrm{M} \&$ \\
\hline i & $\{(\mathrm{a}, \mathrm{e}: \mathrm{gth}: 4),(\mathrm{a}, \mathrm{dji}: 1),(\mathrm{b}, \mathrm{e}, \mathrm{g}: 2),(\mathrm{b}, \mathrm{d}: 1$ \\
\hline $\mathrm{h}$ & $\{(\mathrm{a}, \mathrm{c}, \mathrm{s}: 3),(\mathrm{a}, \mathrm{d}: \mathrm{l}),(\mathrm{c}, \mathrm{f}, \mathrm{g}: \mathrm{l})>$ \\
\hline$S$ & $\{(\mathrm{a}, \mathrm{e}: 4),(\mathrm{a}, \mathrm{d}: 1),(\mathrm{b}, \mathrm{e}: 3),(\mathrm{c}, \mathrm{f}: 2)\}$ \\
\hline f & $\{(\mathrm{c}: 2)\}$ \\
\hline $\mathrm{E}$ & $\{(\mathrm{a}: 4),(\mathrm{b}: 3)\}$ \\
\hline $\mathrm{D}$ & $\left.\left.\mathrm{K}^{*}: 2 \mathrm{Hb}: 2\right)\right\}$ \\
\hline
\end{tabular}

Support count dari setiap item pada conditional pattern base dijumlahkan, lalu item yang memiliki jumlah support count lebih besar sama dengan minimum support count \% akan dibangkitkan dengan conditional FP-tree.

\begin{tabular}{|c|c|c|}
\hline Suffix & Conditional Pattern Base & $\begin{array}{l}\text { Condition } \\
\text { al FP- }\end{array}$ \\
\hline $\mathrm{J}$ & & \\
\hline I & $\left\{\left({ }_{\mathrm{a}}, \mathrm{egJi}: 4\right),\left({ }_{\mathrm{a}}, \mathrm{d} 3 \mathrm{i}: \mathrm{l}\right),\left(\mathrm{b},{ }^{\wedge}: 2\right),(\mathrm{b}\right.$, & $\{(\mathrm{a}: 5, \mathrm{~b}: 3$, \\
\hline $\mathrm{R}$ & $!(\mathrm{w} 3 \mathrm{i}(\mathrm{a}, \pm \mathrm{l}),(\mathrm{ci} 5 \mathrm{l})\}$ & $\{(\mathrm{a}: 2: \mathrm{s}: 4)\}$ \\
\hline G & $\{(\mathrm{a}, \mathrm{e}: 4),(\mathrm{a}, \mathrm{d}: 1$ & $\{(\mathrm{a}: 2, \mathrm{e}: 7, \mathrm{f}$ \\
\hline $\mathrm{F}$ & tfc:2)3 & \\
\hline E & $\{\mathrm{MW}>3 »$ & $\{(\mathrm{a}: 4, \mathrm{~b}: 3)$ \\
\hline $\mathrm{D}$ & & $\{(a: 2, b: 2)$ \\
\hline
\end{tabular}

merupakan lintasan tunggal, maka didapatkan frequent itemset dengan melakukan kombinasi item untuk setiap conditional FP-tree. Jika bukan lintasan tunggal, maka dilakukan pembangkitan FPgrowth secara rekursif. 


\begin{tabular}{|l|l|l|}
\hline $\begin{array}{l}\text { Suffi } \\
\boldsymbol{x}\end{array}$ & Conditional Pattern Base & $\begin{array}{l}\text { Frequent } \\
\text { Itemset }\end{array}$ \\
\hline J & $\{(\mathrm{Mg} 1 \mathrm{~K} x d t o i l$ Id xgjim.d: 1 & $(\mathrm{dj}): 3,(\mathrm{gj}>$ \\
\hline I & $((3$, egdi:4Mxd4i:l),(b,eg:2), & $(\mathrm{a} 4): 5,(\mathrm{bj})$ \\
\hline H & & C\&h $) 4$ \\
\hline G & $\{(\mathrm{a}, \mathrm{e}: 4),(\mathrm{a}, \mathrm{d}: 1):\{\mathrm{b}, \mathrm{e}: 3),(\mathrm{c}, \mathrm{f}: 2$ & $(<\boldsymbol{\&} ?$ \\
\hline F & $\{(<=2) 5$ & \\
\hline E & & $(\mathrm{a}, \mathrm{e}): 4$, \\
\hline D & $\{(\mathrm{a}: 2),(\mathrm{b}: 2) \mathrm{J}$ & \\
\hline
\end{tabular}

selanjutnya menghitung nilai support dan confidence-nya. Item yang dihitung nilai support dan confidence-nya yaitu: $\{\mathrm{d}, \mathrm{j}\}$, $\{\mathrm{g}, \mathrm{j}\},\{\mathrm{a}, \mathrm{i}\},\{\mathrm{b}, \mathrm{i}\},\{\mathrm{g}, \mathrm{i}\},\{\mathrm{h}, \mathrm{i}\},\{\mathrm{g}, \mathrm{h}\},\{\mathrm{e}, \mathrm{g}\}$, $\{a, e\},\{b, e\}$.

Support $(A)=\quad \frac{\text { Jumlah Transaksi mengendung A }}{\text { Total Transaksi }}$

sedangkas nilai support dari 2 item diperoleh dari numus benkut:

$$
\operatorname{Support}(A C \text { B })=\quad \frac{\text { Jurtiah Transaksi mengangung A dan } B}{\text { Total Transaksi }}
$$

Menghitung nilai Confidence :

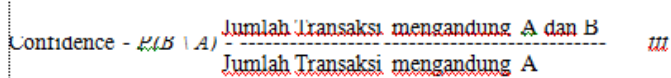

Adapun hasil darı nila1 support dan nilai confidence untuk lebih jelasnya dapat dilihat pada tabel berikut :

\begin{tabular}{|c|c|c|c|}
\hline Fokr Melanggar & Maks Aksu Melanggar & Support & Confidenser \\
\hline Mobal & Ramba-rambs & $21,43 \%$ & $79 \%$ \\
\hline Rambs-rambe & Mobd & $21,43 \%$ & $50 \%$ \\
\hline $\operatorname{STM}$ & Rambo-rambo & $21,43 \%$ & $27,27 \%$ \\
\hline Rumbs-rambse & $\operatorname{SIM}$ & $21,43 \%$ & $50 \%$ \\
\hline Pelajar & Perbanglapan & $35,71 \%$ & $83.33 \%$ \\
\hline Perbenglapan & Pelajar & $35,71 \%$ & $50 \%$ \\
\hline Mobal & Perlenglapan & $21,43 \%$ & $60 \%$ \\
\hline Perienglapan & Mobd & $21,43 \%$ & $30 \%$ \\
\hline $\operatorname{siM}$ & Perienglapan & $42.86 \%$ & $54.55 \%$ \\
\hline Perhenglapan & $\mathrm{sTM}$ & $42,96 \%$ & $60 \%$ \\
\hline STNK & Periengtapan & $35,71 \%$ & $83,33 \%$ \\
\hline Perienglapan & STNR & $35,71 \%$ & $50 \%$ \\
\hline $\operatorname{siM}$ & STNK & $28,57 \%$ & $36,36 \%$ \\
\hline STNR & SIM & $28,57 \%$ & $66,67 \%$ \\
\hline Monos & STM & $50 \%$ & $100 \%$ \\
\hline $\operatorname{siM}$ & 2Notors & $50 \%$ & $63,64 \%$ \\
\hline Pelajar & Notose & $28.57 \%$ & $66,67 \%$ \\
\hline Monse & Pelajar & $28.57 \%$ & $57,14 \%$ \\
\hline Karyaman & Motose & $21,43 \%$ & $60 \%$ \\
\hline Motose & Karyanan & $21.43 \%$ & $42.86 \%$ \\
\hline
\end{tabular}

rule dapat dilihat pada tabel berikut :

\begin{tabular}{|l|l|l|l|}
\hline $\begin{array}{l}\text { IjJbt.Xtelan } \\
\text { ggar }\end{array}$ & $\begin{array}{l}\text { ltMsa Akan } \\
\text { Melanggar }\end{array}$ & Support & $\begin{array}{l}\text { Confide } \\
\text { nce }\end{array}$ \\
\hline Pelajar & Parian Ekap & $35,71 \%$ & $83,33 \%$ \\
\hline SIM & Parlanskapan & $42,86 \%$ & $54,55 \%$ \\
\hline STNK & $\begin{array}{l}\text { Parian Ekap } \\
\text { an }\end{array}$ & $35,71 \%$ & $83,33 \%$ \\
\hline Motor & SIM & $50 \%$ & $100 \%$ \\
\hline
\end{tabular}

Dari rule yang dihasilkan diatas, jika item a (pelajar) maka melanggar item $\mathrm{i}$ (perlengkapan), jika item g (SIM) maka melangar item i (Perlengkapan), jika item $\mathrm{h}$ (STNK) maka melanggar item (Perlengkapan), jika item e (Motor) maka melanggar item g (SIM).

\section{SIMPULAN}

Algoritma FP-Growth merupakan salah satu metode yang tepat untuk diterapkan pada data pelanggaran lalu lintas karena membantu kepolisian dalam menganalisis pola pelanggaran yang sering dilanggar. Hal ini membantu kepolisan untuk meningkatkan kinerja Kepolisian.

Dari hasil analisis menunjukkan bahwa pelanggaran yang sering dilanggar tersebut tepat sesuai dengan data yang didapat. Hal ini terjadi dikarenakan masih kurangnya kepedulian pengendara untuk mematuhi aturan yang ada.

\section{DAFTAR PUSTAKA}

[1] POLRESTA PADANG

[2] Pramudiono, Iko. 2003. Pengantar Data Mining : Menambang Permata Pengetahuan di Gudang Data. http:// www.ilmukomputer.com, tanggal akses 24 April 2014.

[3] Erwin, 2009. Analisis Market Basket Dengan Algoritma Apriori dan FPGrowth. Jurnal Generic, vol. 4.

[4] Irdiansyah,Enur.(2010).”Penerapan Data Mining Pada Penjualan Produk Minuman Di PT. Pepsi Cola Indobeverages Menggunakan Metode Clustering”. Bandung.Univeritas Komputer Indonesia.

[5] Subekti Mujiasih (2011). Pemanfatan Data Mining Untuk Prakiraan Cuaca 
[6] Sani Susanto dan Dedy Suryadi (2010).

Pengantar Data Mining. Yogyakarta.

Penerbit Andi.97.

[7] Nugroho Wandi. et all (2012). Pengembangan Sistem Rekomendasi Penelusuran Buku dengan Pengendalian Association Rule Menggunakan Algoritma Apriori (Studi Kasus Badan Perpustakaan dan Kearsipan Provinsi Jawa Timur)

[8] Kusrini dan Emha Taufig Luthfi (2009). Algoritma Data Mining. Yogyakarta. Penerbit Andi.3-12.

[9] R.Agrawal, C. Aggarwal, dan V. V. V. Prasad. "A tree projection algorithm for generation of frequent itemsets". Pada J. Parallel dan Distributed Computing, 2000. 